\title{
Do housing tenure and car access predict health because they are simply markers of income or self esteem? A Scottish study
}

\author{
Sally Macintyre, Anne Ellaway, Geoff Der, Graeme Ford, Kate Hunt
}

\begin{abstract}
Objective-To investigate relations between health (using a range of measures) and housing tenure or car access; and to test the hypothesis that observed relations between these asset based measures and health are simply because they are markers for income or self esteem.

Design-Analysis of data from second wave of data collection of West of Scotland Twenty-07 study, collected in 1991 by face to face interviews conducted by nurse interviewers.

Setting-the Central Clydeside Conurbation, in the West of Scotland.

Subjects-785 people (354 men, 431 women) in their late $30 \mathrm{~s}$, and 718 people (358 men, 359 women) in their late 50s, participants in a longitudinal study.

Measures-General Health Questionnaire scores, respiratory function, waist/hip ratio, number of longstanding illnesses, number of symptoms in the last month, and systolic blood pressure; household income adjusted for household size and composition; Rosenberg self esteem score; housing tenure and car access.

Results-On bivariate analysis, all the health measures were significantly associated with housing tenure, and all except waist/hip ratio with car access; all except waist/hip ratio were related to income, and all except systolic blood pressure were related to self esteem. In models controlling for age, sex, and their interaction, neither waist/hip ratio nor systolic blood pressure remained significantly associated with tenure or car access. Significant relations with all the remaining health measures persisted after further controlling for income or self esteem.

Conclusions-Housing tenure and car access may not only be related to health because they are markers for income or psychological traits; they may also have some directly health promoting or damaging effects. More research is needed to establish mechanisms by which they may influence health, and to determine the policy implications of their association with health.

(F Epidemiol Community Health 1998;52:657-664)
\end{abstract}

Sociology Unit, 6

Lilybank Gardens,

Glasgow G12 8RZ

Correspondence to:

Professor Macintyre.

Accepted for publication 21 November 1997
In Britain and elsewhere, whether or not a household owns the dwelling in which it lives, and owns or has access to a car or van, predict the life expectancy and health of its members.
People in rented properties (particularly in the public rented sector), and those in households without a car, have higher death rates than people in owner occupied or car owning households. ${ }^{1-3}$ In the Office of National Statistics (ONS) Longitudinal Study, a follow up of a $1 \%$ sample from the 1971 British Census, mortality in 1981-89 was 34\% higher for men and $32 \%$ higher for women living in homes rented from the local authority than for those living in owner occupied homes; and 41\% higher for men and $24 \%$ higher for women in non-car owning households than those in car owning households. ${ }^{3}$ These associations persist within social class groups; in the UK there is more variation in mortality between owners and tenants within occupational social class groups than there is between social classes within tenure categories. ${ }^{124}$ Such relations are also observable within grades of the civil service in the UK (for example, top grade civil servants without cars have higher mortality than those with cars ${ }^{5}$ ).

There are fewer data available on the relation between tenure or car access and health, compared with mortality, but these have shown that owner occupation and access to a car are associated with better health. For example, the British Health and Lifestyle Survey found that owner occupiers had better health than tenants, whether in non-manual or manual social classes. ${ }^{6}$ In the 1958 British Birth Cohort study those living in owner occupied households had better health at age 7 and 23 (using five different health measures) than those living in local authority housing. ${ }^{7}$ Rates of long term illness reported in the 1991 British census were higher among public sector tenants and those without access to a car; this association persisted within each social class group and there was a multiplicative relation, so that the highest rates were reported by social class IV and V local authority renters with no cars. ${ }^{8}$

Consultation rates in general practice have also been shown to be related to tenure, with lower rates among owner occupiers after controlling for a wide range of sociodemographic characteristics and health status. ${ }^{9}$ In Sweden, living in rented accommodation was associated not only with increased mortality risks, but also with higher rates of GP consultations and increased length of consultation, controlling for sociodemographic variables and educational levels. ${ }^{10}$ In the UK, having access to more than one car reduces the probability that a person will consult their GP, 
and living in rented accommodation increases the likelihood. ${ }^{11}$

Most research in social epidemiology has used these asset based measures as proxies for measures of income, wealth, or social class. They are certainly related strongly to income-in an examination of the validity of commonly used census indicators as "predictors" of income it was found that three key correlates of low income were no car, no owned home, and no job. ${ }^{12}$ It has been suggested that these household asset measures are more refined indicators of material well being than social class or employment grade or income, ${ }^{13}{ }^{14}$ particularly as occupational social class measures may be inappropriate for large sections of the population (for example, women, the very young or old, the unemployed), and information about income is not currently collected at census, and is difficult to collect in surveys. The absence of information on income in official statistics in Europe has led to the widespread use of proxies for individual income data. For example, housing tenure and car access are widely used to classify areas, ${ }^{15}{ }^{16}$ or people or households, ${ }^{1217}$ by level of material deprivation. Although there is an extensive debate about what should be included in deprivation indices as proxies for material well being, ${ }^{18} 19$ much of this centres round the statistical properties of the variables rather than on their meaning or why they should be so predictive of other life chances such as health. The usual assumption is that they have little direct bearing on health but are markers for other characteristics: "For example, car access (a factor included in many indices) is perhaps the best social correlate of health status. ${ }^{15}{ }^{16}$ But no one would suggest that the reality of owning a car has much direct effect on health. Car access principally reflects income and this in turn a whole range of factors relating to access to resources and power". ${ }^{20}$

And in a discussion of whether overcrowding is associated with an increased risk of mortality: "While both cars and tenure are social indicators and are not assumed to have a direct causal effect on mortality, over-crowding may, of itself, lead to a higher likelihood of some kind of diseases". ${ }^{21}$

Thus when tenure and car access are used in health research it is usually as indicators of assumed underlying causal factors such as income or social position, rather than as having any directly health promoting or health damaging effects. This tends to imply that observed relations between tenure or car access and longevity or health are spurious, arising from the close association between income and tenure or car access. Such models tend to beg the question of how income influences health if not through mechanisms associated with living and working conditions, including housing and transport. An alternative model is that tenure and car access are among the numerous factors intervening between income and health; that is, that housing and transport are among the health promoting resources to which income provides access. In this model, income (and associated assets such as savings, earning potential, and credit worthiness) allows one to choose to buy a dwelling, probably in better condition and in a better physical and social environment than dwellings in the public rented sector. ${ }^{22}$ Income and its associated advantages also allow one to choose to buy a vehicle instead of using public transport; and although there are health damaging aspects of car ownership (see below), there are also health promoting aspects.

A different version of the idea that tenure and car access are simply markers for income is that they are markers for psychological traits (such as self efficacy, or self esteem), which predict both health and the likelihood of home or car ownership. This model suggests that the direct relation is between the psychological characteristics and health, and that the observed relation between housing tenure or car access and health is spurious, arising because people with these traits are more likely to have bought their homes and cars. An alternative conceptualisation is that owning a home and car may increase health promoting psychological characteristics such as self esteem (that is, that self esteem is one of the mechanisms linking tenure or car access and health).

Because most health studies do not have data on both income and tenure or car access (indeed it is usually the lack of information on income that leads researchers to use tenure or car access as proxies for income), the issue of whether there is any additional effect of these on health when income is taken into account has rarely been examined. Similarly, studies that have examined psychological factors, health and tenure or car access have tended to treat the last two as markers for socioeconomic status and have not examined whether they have any impact on health controlling for psychological factors. ${ }^{23}{ }^{24}$ There is therefore no empirical published evidence that would allow one to choose between the competing models outlined above.

However, research on housing, neighbourhood conditions, and health suggests that there are various possible mechanisms by which housing tenure might influence health. ${ }^{25} 26$ Dampness, mould, and overcrowding, which are related to respiratory and chronic illness and psychological distress, ${ }^{27-33}$ are more common in public sector homes. ${ }^{30}{ }^{31}$ Public sector tenants are more likely than owner occupiers to live in flats and on run down estates ${ }^{34}$; and dwelling type (that is, whether a flat or house), and associated characteristics such as the quality and perceived safety of the surrounding environment, have been found to be associated with mental and physical health. ${ }^{28}{ }^{35-42}$ Ontological security, ${ }^{43}$ particularly as it relates to protection, personalisation, and prestige, has also been linked both with psychological and physical health and with home ownership. ${ }^{44-47}$

Car use can be health damaging or health promoting. Motor transport pollutes the environment (particularly in crowded urban areas), causes accidents to pedestrians, cyclists and other vehicle occupants, contributes to raised blood pressure and obesity levels by reducing 
Table 1 Distribution of tenure and car access by sex and cohort

\begin{tabular}{|c|c|c|c|c|c|c|c|c|c|c|c|c|}
\hline & \multicolumn{2}{|c|}{$\begin{array}{l}\text { Owner } \\
\text { occupiers }\end{array}$} & \multicolumn{2}{|c|}{ Tenants } & \multicolumn{2}{|c|}{ Other } & \multirow{2}{*}{$\begin{array}{l}\text { Total } \\
\mathrm{No}\end{array}$} & \multicolumn{2}{|c|}{ Car access } & \multicolumn{2}{|c|}{ No car access } & \multirow{2}{*}{$\begin{array}{l}\text { Total } \\
\text { No }\end{array}$} \\
\hline & No & $\%$ & No & $\%$ & No & $\%$ & & No & $\%$ & No & $\%$ & \\
\hline \multicolumn{13}{|l|}{ Men } \\
\hline late $30 \mathrm{~s}$ & 260 & 73.4 & 89 & 25.1 & 5 & 1.4 & 354 & 279 & 78.8 & 75 & 21.2 & 354 \\
\hline late $50 \mathrm{~s}$ & 199 & 55.6 & 153 & 42.7 & 6 & 1.7 & 358 & 228 & 63.7 & 130 & 36.3 & 358 \\
\hline \multicolumn{13}{|l|}{ Women } \\
\hline late $30 \mathrm{~s}$ & 289 & 67.1 & 137 & 31.8 & 5 & 1.2 & 431 & 315 & 73.1 & 116 & 26.9 & 431 \\
\hline late $50 \mathrm{~s}$ & 188 & 52.4 & 162 & 45.1 & 9 & 2.5 & 359 & 215 & 59.9 & 144 & 40.1 & 359 \\
\hline Total & 936 & 62.3 & 541 & 36.0 & 25 & 1.7 & 1502 & 1037 & 69.0 & 465 & 31.0 & 1502 \\
\hline
\end{tabular}

exercise in vehicle occupants, and raises stress levels among drivers. However, access to a car has the potential to improve health by increasing access to employment, shops selling healthy foods at affordable prices, leisure facilities, social support networks, health services and open space; and by reducing exposure to dangers such as mugging, rape or assault. ${ }^{48-50}$ Car ownership may improve ontological security, and thereby health, through its capacity to protect passengers from external threats, to express the owner's personality, and confer prestige. $^{51}$

In this paper we report on an exploratory analysis of the relation between housing tenure and car access on the one hand, and a range of health measures (covering a variety of domains of health) on the other hand, using data from the West of Scotland Twenty-07 study. We examine the effects of controlling for income or self esteem on observed relations between health and housing tenure or car access, and interactions with sex and with age. The aim is to explore interrelations between these sociodemographic and health measures in more empirical detail than is usually possible, and in particular to test the hypothesis that observed associations between these census variables and health would be removed if you control for income or self esteem.

\section{Methods}

THE SAMPLE

For this analysis we used the two adult cohorts of The West of Scotland Twenty-07 Study, which aims to investigate the processes by which socially structured health inequalities are created and maintained. Full details of the design have been described elsewhere. ${ }^{52}{ }^{53}$ The study consists of prospective surveys of 3000 people comprised of three age groups (aged 15, 35,55 at baseline survey in $1987 / 88$ ) chosen to provide information on the processes affecting the social patterning of health at key points in the life span. It is based on a two stage stratified random sample within the Central Clydeside Conurbation, a predominantly urban area in the west of Scotland, centred on Glasgow city, with a population of 1.7 million in 1981 and 1.5 million in 1991 (around one third of that of Scotland as a whole). The west of Scotland is known to have generally poor health, and the study area had an all cause SMR of 109 relative to Scotland in 1981. However, the individual SMRs of the postcode sectors that form the primary sampling units ranged from 62 to 147 , so a full range of variation in health status is represented in the study.
For the present analyses we used second wave data, collected in 1991, on the middle cohort $(\mathrm{n}=852)$ and the oldest cohort $(\mathrm{n}=$ 858). We exclude the youngest cohort because the meaning and implications of housing tenure and car access are likely to be very different among adolescents compared with adults. The design allows us to examine cohort and sex differences. In the re-interviewed sample there were 778 males and 932 females; 1074 owner occupiers, 604 public sector tenants, 30 with other forms of tenure (including tied accommodation and privately rented furnished or unfurnished dwellings) and two with missing tenure data; and 1186 with household car access, 522 without household car access and two with missing data on car access.

\section{VARIABLES}

Variables used in this analysis are: sex, cohort (late 30s and late 50s), housing tenure, car access, household income, self esteem, and a suite of health measures. Less than $2 \%$ of either cohort were from non-white ethnic groups so race was not used in this analysis.

Income is total household income net of tax but including any benefits received. Respondents were asked to specify an actual amount in pounds per week, month or year, or if they were unwilling to do this they could indicate one of 11 income bands on a card shown to them (7-10\% opted to do this, and income values were assigned to them by using the median income of those who had reported actual values falling into that band). Data on income were missing for 148 respondents (18 men and 33 women in their late 30s, 27 men and 70 women in their late 50s). Household income, in pounds per week, was then adjusted for household size and composition, using a set of weights for age, sex, and relationship to respondent. $^{54}$

Self esteem was measured using the Rosenberg self esteem scale ${ }^{55}$ on which scores range from 10 (low) to 40 (high). Self esteem scores were missing for 66 respondents $(10$ men and 10 women in their late $30 \mathrm{~s}, 16$ men and 30 women in their late 50s).

For the purposes of this analysis we used only those respondents with no missing data on tenure, car access, income, or self esteem. This reduced the effective sample size to 1502 respondents. Table 1 shows their distribution by sex, age, and tenure and car access categories.

We selected a range of health measures designed to represent different domains of 
Table 2 Means of health measures, household income, and self esteem by sex, cohort, tenure, and car access

\begin{tabular}{|c|c|c|c|c|c|c|c|c|}
\hline & $\begin{array}{l}\text { GHQ Likert } \\
\text { score }\end{array}$ & $F E V_{1} / h t^{2}$ & $\begin{array}{l}\text { Waist/hip } \\
\text { ratio }\end{array}$ & $\begin{array}{l}\text { GHS illnesses } \\
\text { (n) }\end{array}$ & $\begin{array}{l}\text { Symptoms in } \\
\text { past month } \\
(n)\end{array}$ & $\begin{array}{l}\text { Systolic blood } \\
\text { pressure }\end{array}$ & $\begin{array}{l}\text { Household } \\
\text { income }\end{array}$ & Self esteem \\
\hline & Mean & Mean & Mean & Mean & Mean & Mean & Mean & Mean \\
\hline Sex (significance) & $\dagger$ & $\dagger$ & $\dagger$ & NS & $\dagger$ & t & t & $\dagger$ \\
\hline Male & 2.32 & 1.03 & 0.92 & 0.52 & 3.27 & 131.83 & 213.26 & 31.69 \\
\hline Female & 2.41 & 0.87 & 0.81 & 0.52 & 4.11 & 127.76 & 184.14 & 30.30 \\
\hline Cohort (significance) & NS & $t$ & $t$ & $t$ & $\dagger$ & t & t & t \\
\hline late $30 \mathrm{~s}$ & 2.36 & 1.06 & 0.86 & 0.38 & 3.40 & 120.24 & 214.16 & 31.02 \\
\hline late $50 \mathrm{~s}$ & 2.37 & 0.82 & 0.88 & 0.67 & 4.06 & 140.04 & 180.19 & 30.89 \\
\hline Tenure (significance) & $t$ & $t$ & $\star$ & $\dagger$ & $\dagger$ & $t$ & $t$ & + \\
\hline owner occupier & 2.31 & 1.00 & 0.86 & 0.44 & 3.25 & 128.00 & 242.3 & 31.6 \\
\hline rents & 2.46 & 0.87 & 0.88 & 0.67 & 4.54 & 132.80 & 122.9 & 29.8 \\
\hline other & 2.30 & 0.84 & 0.86 & 0.55 & 3.16 & 125.60 & 161.7 & 32.4 \\
\hline Car access (significance) & $\dagger$ & + & NS & $\dagger$ & $\dagger$ & $t$ & + & + \\
\hline yes & 2.33 & 0.98 & 0.87 & 0.46 & 3.41 & 128.34 & 227.3 & 31.3 \\
\hline no & 2.43 & 0.86 & 0.87 & 0.64 & 4.38 & 132.69 & 132.5 & 30.1 \\
\hline Total & 2.36 & 0.95 & 0.87 & 0.52 & 3.71 & 129.69 & 197.95 & 30.97 \\
\hline correlation with income & $-0.138^{\star \star}$ & $0.248^{\star \star}$ & -0.005 & $-0.135^{\star \star}$ & $-0.174^{\star \star}$ & $-0.077^{\star \star \star}$ & & $0.175^{\star \star}$ \\
\hline correlation with self esteem & $-0.509^{\star \star}$ & $0.131^{\star \star}$ & $0.069^{\star \star}$ & $-0.157^{\star \star}$ & $-0.380^{\star \star}$ & 0.010 & & \\
\hline
\end{tabular}

NS $\mathrm{p} \geqslant 0.05,{ }^{\star} \mathrm{p}<0.5,{ }^{\star \star} \mathrm{p}<0.01,+\mathrm{p}<0.0001$.

health (for example, cardiovascular, anthropometric, self reported physical and mental health conditions, and recent symptoms), and which are known to be associated with socioeconomic status and with mortality and/or poor health. (Poor respiratory function and a high waist to hip ratio, for example, predict premature mortality). We chose to use all the measures in a continuous form to facilitate standard methods of analysis. Some of the 1502 cases had missing data on one or more health measure; these are excluded from the analysis of the relevant measure and their numbers are reported below. The measures used were:

(1) General Health Questionnaire ${ }^{56}$ (12 item GHQ Likert scored; 41 cases missing data). Because the distribution of this variable was highly skewed, we used a log transformation;

(2) Standardised $\mathrm{FEV}_{1}$ (forced expiratory volume in one second-maximum of three readings using a Micro Medical Spirometer, standardised by dividing by the square of height in metres; 22 cases missing);

(3) Waist/hip ratio (waist $(\mathrm{cm}) /$ hip measurement $(\mathrm{cm}) ; 11$ cases missing data);

(4) Number of longstanding illnesses reported (extended version of the standard question from the British General Household Survey $^{57}$; "Do you have any longstanding illness, disability or infirmity? By longstanding I mean anything that has troubled you over a period of time or that is likely to affect you over a period of time?"; no missing data). Because the distribution of this variable was highly skewed, we used a log transformation;

(5) Number of symptoms reported in the last month out of 20 common symptoms ( 0 cases missing.) Because the distribution of this variable was highly skewed we used a log transformation;

(6) Systolic blood pressure (average of two readings on a Hawksley random zero sphygmomanometer, taken in a seated position after a five minute rest; four cases missing data).

ANALYSIS

All analyses were conducted using SPSS for Windows (version 7). To be relevant to the hypotheses being considered, the health meas- ures should show prima facie evidence of association with housing tenure or car access, or both. The analysis began, therefore, by examining the bivariate associations of the health measures with housing tenure and car access, as well as with sex and age cohort. Analysis of variance was used for this. The correlations of income and self esteem with the health measures were also examined at this stage.

Having established the nature of the bivariate relations of housing tenure and car access to the health measures, multivariate analysis was used to determine whether these persisted or disappeared when controlled for income or self esteem. Age and sex were also considered as important potential confounders and the multivariate analyses controlled for this by including age, sex and their interaction in all models before introducing income or self esteem. Then the effect of income, or self esteem, on the health measure was modelled, including any significant interactions with age and/or sex and including quadratic effects where significant. Finally, having controlled for age, sex and income or self esteem in this way, housing tenure and car access are entered and tested for significance. The SPSS General Linear Modelling (GLM) procedure was used for all the multivariate analysis. ${ }^{58}$

To illustrate the magnitude and direction of the association between tenure or car access and health, we present the mean values of each measure by tenure and car access, firstly without controls, secondly having controlled for age, sex, and their interaction, and thirdly having controlled for income or self esteem (and any interactions with age or sex where significant); this allows us to examine the degree of attenuation resulting from these controls.

\section{Results}

Table 2 gives mean values for each of the health measures, and for income and self esteem, by sex, cohort, tenure, and car access. There are significant sex differences in all health measures except number of longstanding illnesses reported; significant age differences in all 
Table 3 Mean values of health measures, and significance levels of differences, by tenure and car access, before and after adjustment

\begin{tabular}{|c|c|c|c|c|c|c|c|c|}
\hline & \multicolumn{2}{|c|}{ Unadjusted } & \multicolumn{2}{|c|}{ Adjusted for age and sex } & \multicolumn{2}{|c|}{$\begin{array}{l}\text { Adjusted for age, sex, and } \\
\text { income }\end{array}$} & \multicolumn{2}{|c|}{$\begin{array}{l}\text { Adjusted for age, sex, and self } \\
\text { esteem }\end{array}$} \\
\hline & Mean & Significance & Mean & Significance & Mean & Significance & Mean & Significance \\
\hline \multicolumn{9}{|l|}{ GHQ Likert } \\
\hline Owner occupier & 2.31 & $\dagger$ & 2.36 & $\star$ & 2.34 & $\dagger$ & 2.34 & $\star \star$ \\
\hline Tenant & 2.46 & & 2.37 & & 2.41 & & 2.42 & \\
\hline Other & 2.30 & & 2.37 & & 2.38 & & 2.29 & \\
\hline Car access & 2.33 & $\dagger$ & 2.36 & $\star \star$ & 2.35 & $\star \star$ & 2.35 & $\star$ \\
\hline No car access & 2.43 & & 2.37 & & 2.40 & & 2.41 & \\
\hline \multicolumn{9}{|l|}{ FEV/Height ${ }^{2}$} \\
\hline Owner occupier & 1.00 & $\dagger$ & 0.97 & $\dagger$ & 0.98 & $\dagger$ & 0.97 & $\dagger$ \\
\hline Tenant & 0.87 & & 0.92 & & 0.89 & & 0.91 & \\
\hline Other & 0.84 & & 0.91 & & 0.90 & & 0.92 & \\
\hline Car access & 0.98 & $\dagger$ & 0.96 & $\dagger$ & 0.97 & $\dagger$ & 0.96 & $\dagger$ \\
\hline No car access & 0.86 & & 0.91 & & 0.89 & & 0.91 & \\
\hline \multicolumn{9}{|l|}{ Waist/hip ratio } \\
\hline Owner occupier & 0.864 & * & 0.869 & NS & 0.868 & $\star \star$ & 0.869 & $\dagger$ \\
\hline Tenant & 0.876 & & 0.866 & & 0.870 & & 0.868 & \\
\hline Other & 0.863 & & 0.868 & & 0.869 & & 0.867 & \\
\hline Car access & 0.867 & NS & 0.870 & NS & 0.868 & NS & 0.869 & $\star \star$ \\
\hline No car access & 0.872 & & 0.866 & & 0.870 & & 0.866 & \\
\hline \multicolumn{9}{|l|}{ No of GHS illnesses } \\
\hline Owner occupier & 0.44 & $\dagger$ & 0.50 & $\dagger$ & 0.48 & $\dagger$ & 0.49 & $\dagger$ \\
\hline Tenant & 0.67 & & 0.55 & & 0.58 & & 0.57 & \\
\hline Other & 0.55 & & 0.56 & & 0.57 & & 0.52 & \\
\hline Car access & 0.46 & $\dagger$ & 0.50 & $\dagger$ & 0.49 & $\dagger$ & 0.50 & $\dagger$ \\
\hline No car access & 0.64 & & 0.55 & & 0.58 & & 0.57 & \\
\hline \multicolumn{9}{|l|}{ No of symptoms } \\
\hline Owner occupier & 3.25 & $\dagger$ & 3.65 & $\dagger$ & 3.35 & $\dagger$ & 3.48 & $\dagger$ \\
\hline Tenant & 4.54 & & 3.81 & & 4.15 & & 4.13 & \\
\hline Other & 3.16 & & 3.83 & & 3.94 & & 3.32 & \\
\hline Car access & 3.41 & $t$ & 3.66 & $t$ & 3.53 & $\star$ & 3.55 & $\star \star$ \\
\hline No car access & 4.38 & & 3.82 & & 4.12 & & 4.07 & \\
\hline \multicolumn{9}{|l|}{ Systolic BP } \\
\hline Owner occupier & 128.00 & $\dagger$ & 128.51 & NS & 128.33 & NS & 128.52 & $\star$ \\
\hline Tenant & 132.80 & & 131.63 & & 131.93 & & 131.61 & \\
\hline Other & 125.60 & & 132.20 & & 132.29 & & 132.19 & \\
\hline Car access & 128.34 & $\dagger$ & 128.76 & NS & 128.64 & NS & 128.77 & NS \\
\hline No car access & 132.69 & & 131.78 & & 132.03 & & 131.76 & \\
\hline
\end{tabular}

NS $\mathrm{p} \geqslant 0.05,{ }^{\star} \mathrm{p}<0.05,{ }^{\star \star} \mathrm{p}<0.01,+\mathrm{p}<0.0001$

health measures except GHQ; significant tenure differences in all health measures; and significant car access differences in all measures except waist/hip ratio. Income and self esteem differ significantly by all these sociodemographic variables. Men, younger respondents, owner occupiers and those with household car access have significantly higher household income and self esteem (though those in "other" tenure have higher self esteem than owners or renters). Income is significantly correlated with all the health measures except for waist/hip ratio, and self esteem is significantly related to all of them except systolic blood pressure.

Table 3 shows the unadjusted means for each of the health measures in column 1 , means adjusted for sex and age in column 2 , means adjusted for sex, age, and income in column 3, and for sex, age, and self esteem in column 4 (adjusted means are derived from the predicted values in the model). This table also shows significance levels for tenure and car access within each of these models.

In models controlling for age and sex, housing tenure and car access were no longer significantly associated with systolic blood pressure or waist/hip ratio (column 2). (Waist/ hip ratio was initially only weakly associated with housing tenure, and not associated with car access; and showed interactions with sex and age (see below)). After controlling for income in addition to age and sex, tenure and car access were both still significantly associated with all of the remaining health measures, and tenure became significantly related to waist/hip ratio (column 3). After controlling for self esteem in addition to age and sex, tenure and car acess were both still significantly associated with all the remaining health measures, and tenure became significantly associated with systolic blood pressure (column 4). Thus none of the health measures that were significantly associated with tenure or car access after controlling for age and sex subsequently ceased to show significant associations with tenure or car access after controlling either for income or self esteem.

The effect of controlling for income or self esteem on the difference in means between tenure or car access groups was not great (compare column 2 with columns 3 and 4 ) and in the case of some health meaures the difference between means was actually larger after adjustment for income or self esteem (for example, $\mathrm{FEV}_{1}$ and the $\log$ of GHS illnesses). Thus not only did controlling for income or self esteem not render observed associations statistically non-significant, but it did not greatly attenuate, and in some cases increased, the magnitude of the differences by tenure or car access.

Although not the focus of this paper, interactions were examined and can briefly be reported. There were statistically significant interactions of tenure with sex on respiratory function (with steeper slopes for women) and on number of symptoms in the last month (with steeper slopes for men), of tenure with age on waist/hip ratio (with steeper slopes for 
the younger cohort), and of car access with sex on waist/hip ratio (with steeper slopes for women). The significant interactions of tenure with age on waist/hip ratio, and of tenure with sex for respiratory function, still remained after controlling for income; the interactions of tenure with sex on the number of symptoms, and of car access with sex on waist/hip ratio, were no longer significant after controlling for income. There were no significant interactions of sex or age with self esteem on any of the health measures.

\section{Discussion}

We have shown that tenure, car access, household income, and self esteem are related to a range of health measures, in the direction that would be predicted by previous work - that is, owner occupation, having access to a car, higher income and higher self esteem predict better recent mental health, better respiratory function, smaller waist/hip ratio, fewer longstanding illness conditions, fewer symptoms in the previous month, and lower blood pressure.

Initially observed significant bivariate relations between tenure or car access and these health measures persisted in models that adjusted firstly for age, sex and their interaction (with the exception of systolic blood pressure and waist/hip ratio), and secondly for either income or self esteem. We interpret this to mean that tenure and car access have some association with these health measures, independently of income or self esteem, rather than tenure and car access simply being markers of (that is, confounded with) income or self esteem.

The attenuation of the initial bivariate relations after adjustment for income or self esteem is not great, and in some cases (for example, $\mathrm{FEV}_{1}$ and $\log \mathrm{GHQ}$ scores) the difference by tenure or car access increases after adjustment for income or self esteem. It may seem surprising that the attenuation is not greater, as income and self esteem are strongly associated with tenure and car access (see table 2). However, there is still considerable variation in income within tenure or car access groups, and it is not possible to "read off" income in any determinate way from these categories. For example, it is unlikely that non-car ownership among well paid people such as very senior civil servants implies that they cannot afford a car; it may instead reflect other factors such as having access to a chauffeur driven car, disability, or personal or political preferences. ${ }^{5}$

In this analysis we have had to use current household income as self reported by the respondents. This is the income measure usually available in studies of the relation between income and health, but we are aware of its deficiencies. Current income may not reflect lifetime income or other assets such as savings or earning power; and we cannot assess household expenditure or the distribution of income within households. Similarly we have used self esteem in this analysis because it was available to us; a better test of whether the tenure or car access relation with health is confounded with psychological traits associ-

\section{KEY POINTS}

- Housing tenure and car access have been shown to be associated with mortality and morbidity.

- It is often suggested that this is just because tenure and car ownership reflect income or psychological traits.

- We found that tenure and car access were still related to a range of health measures after controlling for income and self esteem.

- This suggests that we need to examine the health promoting or damaging effects of housing tenure and car access.

ated with both would be to examine the relation controlling for self efficacy or mastery. Thus the fact that controlling for income and self esteem did not reduce the observed asociations between tenure or car ownership and health measures may be because of the crudity of our measures of income and psychological traits.

It could be argued that tenure and car access are no longer important aspects of social inequalities because of reduced provision of public sector rented properties, and increased car access, over the past decade or two. However, the 1991 census indicated that a substantial proportion of the population still lived in rented properties $(32 \%$ in the UK and $48 \%$ in Scotland) or had no car access (43\% in the UK and $47 \%$ in Scotland). ${ }^{59}$ There are concerns over the deleterious condition of housing in the private and public rented sector $^{2130}$ and that the stock of good quality houses in the public sector has been depleted through the sale of council housing under the Right to Buy legislation. ${ }^{60}$ The slight growth in car ownership since the 1981 census was mainly caused by additional cars in already car owning households. ${ }^{61}$ Recent evidence has shown that renting a home is a highly significant indicator of low income with a larger effect for those without access to a car and that this effect is larger in 1990 than in $1983 . .^{62}$ The fact that the study reported here and the last census (both using information collected in 1991) both found these measures to be associated with poor health suggests that these are still important dimensions of stratification whose association with health needs further investigation.

Assertions that housing tenure and car access are simply markers for income (or more generally, social class or material well being) and have no direct relevance for health or health policy tend to beg the question of how income or social class affect health if not through potential access to health promoting possessions or activities. They sometimes appear to assume that income or social class have direct influence on health, rather than operating through specific mechanisms, whether material (for example, exposure to pathogens, protection from environmental threats, diet, exercise, etc) or psychosocial (for 
example, social support, coping mechanisms, self esteem, self efficacy, placement in social hierarchies, etc). In the 19 th century public health movement the idea that housing conditions were a key mediator of the relation between social class and life expectancy was commonplace ${ }^{63-65}$; with subsequent rises in living standards it is interesting that much current theorising about inequalities in health tends to ignore the role of housing or transport as possibly contributing to observed associations between social class and health or longevity. If we are to increase our understanding of exactly how, under particular social circumstances, social position influences health, then it is important to examine housing tenure and car access, and their relation to health, empirically rather than simply assuming that they are only "markers" for other properties of people such as income or psychological characteristics, especially when we do not have good empirical models of how income or psychological characteristics themselves influence health.

We suggest that further work needs to be done to explore more systematically the interrelation between tenure and car ownership and both health and other measures of material and social well being, and we will be undertaking such analysis as part of a study recently funded under the ESRC Health Inequalities programme. This will examine the use of cars and homes as well as their social meanings.

1 Goldblatt P. Social class differences in mortality. In: MascieTaylor N, ed. The biology of social class. London: Oxford University Press, 1990:24-58.

2 Goldblatt P. Mortality and alternative social classifications. In: Goldblatt P, ed. Longitudinal study: mortality and social organisation. London: HMSO, 1990:163-92.

3 Filakti H, Fox J. Differences in mortality by housing tenure and by car access. Popul Trends 1995;81:27-30.

4 Fox A, Goldblatt P. Socioeconomic differentials in mortality 1971-1975. London: HMSO, 1982.

5 Smith GD, Shipley MJ, Rose G. Magnitude and causes of socioeconomic differentials in mortality - further evidence from the Whitehall Study. 7 Epidemiol Community Health from the Whiteh
1990;44:265-70.

6 Blaxter M. Health and lifestyles. London: Tavistock Routledge, 1990

7 Fogelman K, Fox A, Power C. Class and tenure mobility: do they explain social inequalities in health among young adults in Britain? In: Fox J ed. Health inequalities in European countries. Aldershot: Gower, 1989:333-52.

8 Gould MI, Jones K. Analyzing perceived limiting long-term illness using UK census microdata. Soc Sci Med 1996;42: 857-69.

9 Carr-Hill R, Rice N, Roland M. Socioeconomic determinants of rates of consultation in general practice based on fourth national morbidity survey of general practices. $B M \mathscr{F}$ 1996;312:1008-13.

10 Sundquist J, Johansson SE. Self reported poor health and low educational level predictors for mortality: A population based follow up study of 39156 people in Sweden. $\mathcal{F}$ Epidemiol Community Health 1997;51:35-40.

11 Benzeval M, Judge K. Access to health-care in England continuing inequalities in the distribution of GPs. $\mathcal{F}$ Public continuing inequalities in the

12 Davies H, Joshi H, Clarke L. Is it cash the deprived areas are short of? Research on the 1991 Census. Newcastle upon Tyne: University of Newcastle upon Tyne, 1993.

13 Davey Smith G, Egger M. Socioeconomic differences in mortality in Britain and the United States. Am F Public Health 1992;82:1079-81.

14 Moser K, Pugh H, Goldblatt P. Inequalities in women's health: looking at mortality differentials using an alternative approach. BMF 1988;296:1221-4.

15 Townsend P, Phillimore P, Beattie A. Health and deprivation inequality and the north. London: Routledge, 1988.

16 Carstairs V, Morris R. Deprivation and health in Scotland. Aberdeen: Aberdeen University Press, 1991

17 Greenwood D, Packham C, Muir K, et al. How do socioeconomic status and social support influence survival after initial recovery from acute myocardial infarction? Soc Sci Med 1995;40:639-47.

18 Ellaway A. Deprivation and health: an assessment of the utility of a selection of deprivation indices and their relationship with health. Work 1995.
19 Ellaway A. Are single indicators of deprivation as useful as composite indictors in predicting morbidity and mortality: composite indictors in predicting morbity and mortality: Bull 1997;55:283-4.

20 Carr-Hill R, Sheldon T, Thunhurst C. The politics of deprivation indices and health. In: Spencer N, Janes H, eds. Uses and abuses of deprivation indices. Warwick: University of Warwick, 1992.

21 Dale A, Williams M. Overcrowding as an indicator of housing deprivation in the LS. OPCS Longitudinal Newsletter 1993; (8 May):3-6.

22 Macintyre S, McIver S, Sooman A. Area, class and health: Should we be focusing on people or places? fournal of Social Policy 1993;22:213-34

23 Duncan C, Jones K, Moon G. Psychiatric morbidity - a multilevel approach to regional variations in the UK. $\mathcal{F}$ Epidemiol Community Health 1995;49:290-5.

24 Baker D, Taylor H, and the Survey Team of the Avon Longitudinal Study of Pregnancy and Childhood. Inequality in health and health service use for mothers of young children in south west

25 Ellaway A, Macintyre S. Does housing tenure predict health in the UK because it exposes people to different levels of housing related hazards in the home or its surroundings? Health and Place (in press.)

26 Howden Chapman P, Isaacs N, Crane J, et al. Housing and health - the relationship between research and policy. International Fournal of Environmental Health Research 1996;6: 173-85.

27 Platt S, Martin C, Hunt S, et al. Damp housing, mould growth and symptomatic health state. BMF 1989;298: 1643-8.

28 Hunt S, McKenna S. The impact of housing quality on mental and physical health. Housing Review 1992;41:47-9.

29 Hunt S. Emotional distress and bad housing. Health and Hygiene 1990;11:72-9.

30 Scottish Homes. The Scottish House Condition Survey 1991. Edinburgh: 1993.

31 General Registrar's Office. 1991 Census, Report for Strathclyde Region. Edinburgh: HMSO, 1993.

32 Packer CN, Stewart Brown S, Fowle SE. Damp housing and adult health - results from a life-style study in Worcester, England. F Epidemiol Community Health 1994;48:555-9.

33 Hyndman SJ. Housing dampness and health amongst British Bengalis in East London. Soc Sci Med 1990;30:131-41.

34 Kearns A, Bannister J. Neighbourhoods in Scotland. Analysis of the Scottish House Condition Survey (1991). Edinburgh: Scottish Homes, 1995.

35 Fox A, Jones D, Goldblatt P. Approaches to studying the effect of socioeconomic circumstances on geographical differences in mortality in England and Wales. Br Med Bull 1984;40:309-14.

36 Fanning D. Families in flats. BMf 1967;iv:382-6.

37 Birchnell J, Masters N, Deahl M. Depression and the physical environment: A study of young married women on London housing estate. Br F Psychiatry 1988;153:56-64.

38 Blackman T, Evason E, Melaugh M, et al. Housing and health: a case study of two areas in West Belfast. Fournal of Social Policy 1989;18:1-26.

39 Gloag D. Noise and health: public and private responsibility. $B M \Im$ 1980;281:1404-7.

40 McCarthy P, Byrne D, Harrison S, et al. Housing type, housing location and mental-health. Soc Psychiatry 1985; 20:125-30.

41 Sooman A, Macintyre S. Health and perceptions of the local environment in socially contrasting neighbourhoods in Glasgow. Health and Place 1995;1:15-26.

42 Krause N. Neighborhood deterioration and self-rated health in later life. Psychol Aging 1996;11:342-52.

43 Saunders P. A nation of home owners. London: Unwin Hyman, 1990

44 Krantz D, Shultz R. A model of life crisis, control and health outcomes. In: Baum A, Singer J, eds. Advances in environmental psychology. New York: Lawrence Erlbaum, 1980.

45 Despres C. The meaning of home - literature review and directions for future research and theoretical development. fournal of Architectural and Planning Research 1991;8:96-115.

46 McLaferty P, Yip N. The preference for owner-occupation. Environment and Planning A 1993;25:1559-72.

47 Rohe WM, Stegman MA. The effects of homeownership on the self-esteem, perceived control and life satisfaction of low-income people. Fournal of the American Planning Association 1994;60:173-84.

48 Wolf S, Gillham C. Public health versus public policy? An ppraisal of British urban transport policy. Public Health 1991;105:217-28.

49 Bromley R, Thomas C. The retail revolution, the carless shopper and disadvantage. Transactions of British Geographers 1993;18:222-36.

50 Westlake T, ed. Disadvantaged consumer: problems and policies. London: UCL Press, 1993.

51 Nutley S, Thomas C. Spatial mobility and social-change the mobile and the immobile. Sociologia Ruralis 1995;35: 24-39.

52 Macintyre S, Annandale E, Ecob R, et al. The West of Scotland Twenty-07 Study: health in the community. In: Martin C, McQueen D, eds. Readings for a new public health. Edinburgh: Edinburgh University Press, 1989.

53 Ford G, Ecob R, Hunt K, et al. Patterns of class inequality in health through the lifespan - class gradients at 15, 35 and 55 years in the West of Scotland. Soc Sci Med 1994;39. $1037-50$. 
54 Goodman A, Webb S. For richer for poorer. The changing distribution of income in the UK 1961-1991. London: Institute

55 Rosenberg M. Society and the adolescent self image. Princeton, NJ: Princeton University Press, 1965

56 Goldberg D, Williams P. A user's guide to the General Health Questionnaire. Windsor: NFER-NELSON, 1988

57 OPCS. General Household Survey. London: HMSO, 1992.

58 SPSS. SPSS Advanced Statistics 7.0, 1996. General Registrar's Office. 1991 Census Report for Scotland.
Edinburgh: HMSO, 1993.

60 Forrest R, Murie A. Selling the welfare state: the privatisation of public housing. London: RKP, 1988.
61 Farrington J. Car ownership structure and patterns in Scotland. Scottish Geography Magazine 1995;111:98105.

62 Davies H, Joshi H, Clarke L. Is it cash that the deprived are short of? Fournal of the Royal Statistical Society Series a-Statistics in Society 1997;160 (Pt1):107-26.

63 Chadwick E. General report on the sanitary conditions of the labouring population of Great Britain. London: W Clowes, 1842 .

64 Chalmers A. Medical Officer of Health for Glasgow. Health and Housing, 1916.

65 Engels F. The condition of the working class in England 184445. Frogmore: Panther Books, 1969. 